ISSN 2179-345X

Licenciado sob uma Licença Creative Commons

\title{
Psicologia do juiz
}

\section{Psychology of the judge}

\section{Graziella Ambrosio}

Mestre em Direito das Relações Sociais pela Pontifícia Universidade Católica de São Paulo (PUC-SP), Especialista em Direito e Processo do Trabalho pela Faculdade de Direito da Universidade de São Paulo (USP), São Paulo, SP - Brasil, e-mail: gambrosio@bb.com.br

\section{Resumo}

Todo julgamento reflete, inevitavelmente, a personalidade do juiz. Por isso, além de conhecimentos teóricos, o magistrado deve compreender os fatores conscientes e inconscientes que interferem na sentença, pois, como qualquer ser humano, está vulnerável a diversos sentimentos. Esse conhecimento evitará ele rejeite ou aceite, de imediato, os argumentos das partes porque destoantes de suas crenças e valores, bem como possibilitará a adoção de novos pensamentos conforme exija o caso concreto. A personalidade do juiz pode explicar diversos comportamentos, tais como, dificuldade em condenar, atitudes agressivas, falta de paciência, constante posição defensiva, medo, otimismo exagerado, superficialidade, humor instável, etc. Por outro lado, o magistrado está sujeito a mecanismos psíquicos de defesa, como perda de atenção, esquecimento ou desconsideração de detalhes, quando se vê diante de temas ou situações que lhe ocasionam 
sofrimento psíquico. Da mesma forma, experiências anteriores do juiz podem interferir na sentença, gerando comportamentos favoráveis ou desfavoráveis. Por isso, ele deve desenvolver a capacidade de conter dentro de si, durante certo tempo, suas próprias angústias e sentimentos difíceis que Ihe forem despertados pelo processo.

Palavras-chave: Psicologia jurídica. Psicologia do juiz. Personalidade do juiz. Sentença.

\section{Abstract}

Every trial reflects inevitably the personality of the judge. Therefore, in addition to theoretical knowledge, the magistrate must understand the conscious and unconscious factors that interfere with the sentence because, like any human being is vulnerable to various feelings. This knowledge will prevent the judge to reject or accept at once, the arguments of the parties because of their divergent beliefs and values, and enable the adoption of new thoughts as the case requires. The personality of the judge can explain several behaviors, such as difficulty in condemning, aggressive attitudes, lack of patience, constant defensiveness, fear, excessive optimism, superficiality, mood swings etc. On the other hand, the magistrate is subject to psychological defense mechanisms such as loss of attention, forgetfulness or disregard of detail, when faced with issues or situations that cause distress. Similarly, past experience can interfere with the judge's sentence, generating positive or negative behaviors. Therefore, the judge must develop the ability to contain within itself for a time, their own anguish and hard feelings which are aroused by the process.

Keywords: Judicial psychology. Psychology of the judge. The judge's personality. Sentence.

\section{Introdução}

O processo desperta sentimentos em todos os envolvidos, inclusive no juiz. Tais sentimentos decorrem, em uma análise mais aprofundada, dos ajustamentos peculiares que cada indivíduo realiza ao meio, também chamados de personalidade.

A personalidade é constituída de tendências determinantes que desempenham papel ativo no comportamento do indivíduo. Assim, cada

Rev. Direito Econ. Socioambiental, Curitiba, v. 3, n. 2, p. 491-503, jul./dez. 2012 
pessoa possui a sua personalidade, como algo dentro de si que faz a interação de aspectos físicos, temperamentais (tendência herdada) e caracterológicos (influências ambientais, sociais e culturais). $\mathrm{O}$ estudo dos diversos tipos de personalidade permite a compreensão dos variados padrões de respostas para as situações do cotidiano.

O presente artigo se propõe a analisar como a estrutura de personalidade e os diversos sentimentos por ela desencadeados afetam o juiz na prolação de um julgamento. Busca, também, investigar até que ponto a administração dos conteúdos intrapsíquicos pode ser utilizada produtivamente para a tomada de decisão.

\section{A interferência de aspectos psicológicos no ato de julgar}

$\mathrm{O}$ ato de julgar transcende a formação jurídica do juiz. Além de conhecimentos teóricos, a magistratura exige que o juiz perceba como seus aspectos psicológicos e de todos os envolvidos no litígio interferem em sua sentença. Essa visão holística possibilita uma melhor solução para o caso, pois capacita o magistrado a compreender os conteúdos intrapsíquicos que compreendem uma extensa gama de fatores conscientes e inconscientes. Em uma sentença, tem-se muito mais que a simples aplicação das normas jurídicas ao caso concreto.

A percepção do juiz deve alcançar não apenas os fenômenos mentais que o atingem como também os processos psíquicos das partes, dos advogados e das testemunhas. Ele é um ser humano e, como tal, vulnerável a diversos sentimentos que afetam sua decisão. É ingenuidade pensar que o magistrado tem a capacidade de se despir de todas as suas crenças, valores e referências sociais para proferir uma sentença. $O$ juiz pode sentir medo, raiva, amor, compaixão, intolerância, repulsa, revolta, tristeza, prepotência, dentre outros. No entanto, isso não retira dele o compromisso de controle emocional, pois "o desafio é emocionar-se sem se contaminar pelas emoções próprias e dos participantes" (FIORELLI; MANGINI, 2009, p. 175). 
Trata-se de um exercício de reconhecimento e administração dos próprios sentimentos, pois vários recursos emocionais podem ser utilizados produtivamente para a tomada de decisão. Cite-se, como exemplo, o uso da intuição para detectar se uma pessoa mente ou pretende fazê-lo. Pela intuição, o juiz deixa de usar exclusivamente o pensamento racional e os sentidos, para captar algo importante no sujeito. Assim, a intuição pode ser um instrumento útil para a Justiça desde que seja seguida pela verificação objetiva do juiz.

\section{A personalidade do juiz}

Conquanto o julgamento reflita, inevitavelmente, a personalidade do juiz, o conhecimento de seus aspectos emocionais pode evitar que ele aceite ou rejeite, de imediato, os argumentos das partes porque destoantes de seus valores, crenças e sentimentos. Não se pode opor-se à realidade só porque ela é contrária ao seu pensamento pré-constituído. Ainda que tentado a admitir ou repelir tais ideias externas por meio de uma análise superficial dos fatos, o juiz deve conter seu espírito para não descuidar de pontos que podem ser essenciais para o deslinde da causa e que servirão de fundamento para uma decisão mais justa. Não é o caso concreto que deve se adequar ao sistema conceitual do juiz, mas é o magistrado que deve ser capaz de adotar novos pensamentos conforme exija o caso submetido a julgamento. Trata-se de tendência inconsciente do juiz de usar seus próprios valores para julgar a conduta alheia, mas imperfeita na medida em que a análise acurada das circunstâncias que motivaram o comportamento da parte pode levar a decisão em sentido contrário da inicialmente intuída pelo julgador.

Um juiz excessivamente preso a detalhes pode ter uma compreensão inexata dos verdadeiros elementos relevantes para a causa, assim como o magistrado com perfil sintético pode generalizar inadequadamente situações com natureza diversa e que, portanto, comportam julgamentos distintos adaptados às suas peculiaridades. Os altamente sintéticos 
tendem a repetir sentenças aplicadas a casos análogos, baseando-se exclusivamente em sua sensibilidade, mas isso pode levar a decisões injustas. Assim, deve o juiz estar atento ao automatismo com que profere decisões, pois a conduta humana não se enquadra em classes comportamentais rígidas e estanques, sendo múltiplas as causas que motivam o comportamento do homem. É o cuidado para que casos semelhantes não sejam tomados como idênticos, sobretudo se considerada a complexidade de nossa sociedade, que exige decisões judiciais plásticas e mutáveis, devidamente adequadas às circunstâncias da vida social.

A personalidade do juiz pode explicar diversos comportamentos, tais como dificuldade em condenar, atitudes agressivas, falta de paciência, constante posição defensiva, medo, otimismo exagerado, superficialidade, humor instável, ira, indiferença, arrogância, dificuldades de relacionamento, timidez, temores, angústias, frustrações, apatia, compulsões, disciplina, ordem, seriedade, flexibilidade, detalhamento inútil, perfeccionismo, controle, estresse, desgaste, responsabilidade, satisfação, comprometimento, competitividade, dificuldade em lidar com críticas, insegurança, equilíbrio, dentre outros.

A propósito da influência dos diferentes tipos de personalidade do juiz na decisão jurisdicional, o médico psiquiatra David Zimerman afirma que "a capacidade de julgar a realidade exterior depende diretamente de como é o juízo crítico de cada pessoa em relação ao seu mundo interior" (ZIMERMAN, 2002a, p. 103).

Nesse sentido, afirma esse autor que se a personalidade do juiz for depressiva, ele terá sérias dificuldades em condenar alguém, pois abriga sentimentos de culpa e fantasias de que é corresponsável pelos males e tragédias dos outros. Se a personalidade for paranoide, manter-se-á em constante posição defensiva e responderá com atitudes agressivas, pois sua tomada de conhecimentos se processa à margem da realidade. Se a personalidade for maníaca, ele apresentará humor instável e, diante de qualquer frustração, sua manifesta alegria se transformará em ira, pois ostenta um otimismo exagerado para, no fundo, fugir de uma depressão. Se a personalidade for esquizoide, ele terá sérias dificuldades de 
relacionamento, em razão de uma excessiva timidez e medo de ser rejeitado. Se a personalidade for fóbica, ele será especialista na arte de tirar o corpo fora, pois visualiza o mundo com medo, tendo dificuldades em se comprometer com uma delicada decisão judicial. Se a personalidade tiver traços obsessivos, ele se tornará um julgador implacável e radical, sem um mínimo de flexibilidade e podendo se perder em um detalhamento inútil, pois mantém um rígido controle sobre si mesmo que também é imposto sobre os outros. Se a personalidade for histérica, ele apresentará baixíssima capacidade de tolerar frustrações, alternando momentos de maturidade com outros momentos típicos de crianças que não ganham aquilo que querem. Se a personalidade for psicopática, ele não apresentará consideração pelos demais, pois antes de servir aos outros, ele serve-se destes. Se a personalidade for do tipo falsa, ele tenderá a iludir os outros, pois sente uma permanente sensação de vazio e falsidade que o faz aparentar aquilo que, na realidade, não é. Por fim, se a personalidade do juiz for narcisista, ele não tolerará qualquer crítica que ameace a sua autoimagem de proprietário da verdade e da razão, bem como terá a tendência de se cercar de pessoas que o admirem e o aplaudam incondicionalmente, pois pessoas com essa personalidade possuem uma exagerada valorização de si próprios. Além disso, pode o juiz se tornar um péssimo inimigo, capaz de vinganças mesquinhas ou de manifestar indiferença hostil para quem tiver opiniões e iniciativas próprias, diferentes das dele. Adverte o mesmo autor que esses tipos de personalidade não são estanques, mas se sobrepõem e se combinam entre si em um mesmo sujeito, em graus diferentes (ZIMERMAN, 2002a, p. 106-111).

Por outro lado, é evidente que as diferentes personalidades dos juízes enriquecem o Direito, fenômeno social em constante transformação. Caso todas as personalidades fossem iguais, estabelecer-se-ia um ambiente de rigidez mental na judicatura, altamente prejudicial para o florescimento de novas ideias. O que se repudia é a atuação do universo psíquico do juiz sem conhecimento e controle, o que pode gerar indesejados prejulgamentos ou a desconsideração de elementos importantes para o processo só porque destoam dos valores e crenças dos magistrados, bem 
como a influência de fatores emocionais de simpatia ou de antipatia, que se projetam sobre as testemunhas, os advogados e as partes.

\section{A emoção e a decisão}

Além do perfil caracterológico, as emoções também influenciam na atuação do juiz. O próprio magistrado está sujeito a mecanismos psíquicos de defesa, como perda de atenção, esquecimento ou desconsideração de detalhes, quando se vê diante de temas ou situações que lhe ocasionam sofrimento psíquico, ou seja, quando seus valores pessoais são confrontados ou agredidos. Além disso, existe a tendência de o juiz rejeitar argumentos que contrariem suas crenças e aplicar esquemas de pensamentos próprios na valoração de depoimentos e provas. A propósito do tema, David Zimerman afirma que o juiz deve desenvolver empatia, entendida como a capacidade de se colocar no papel do outro, de modo a sentir o verdadeiro sofrimento alheio e, com isso, desenvolver um mínimo de sadio envolvimento afetivo para a solução da causa. Aliás, ressalta esse autor que a falta de um interesse autêntico do juiz pode resultar em falta de sintonia com o trabalho, o qual passa a ser nada além de um "processo unicamente protocolar, monótono e muitas vezes estéril" (ZIMERMAN, 2002b, p. 584-585).

Da mesma forma, experiências anteriores do juiz podem interferir na sentença, gerando comportamentos favoráveis ou desfavoráveis. Essas experiências podem explicar, por exemplo, porque o magistrado involuntariamente tem afeição ou repulsa por mulheres loiras, homens violentos, pais, mães, policiais, vítimas em geral, padres, pastores, médicos, professores, mecânicos, etc. Assim, o equilíbrio para o julgamento só é alcançado por meio do controle do mecanismo psicológico do juiz, que permite o reconhecimento e o direcionamento de tudo o que é captado pelos sentidos.

Sendo assim, David Zimerman defende que o juiz deve desenvolver a capacidade de ser continente, ou seja, poder conter dentro de 
si, durante certo tempo, sem a necessidade de devolver imediatamente, toda a carga de necessidades, demandas e angústias que os interessados no processo projetam dentro dele. E esse atributo deve se estender ainda para a autocontinência, para que o juiz possa conter dentro de si suas próprias angústias e sentimentos difíceis que lhe foram despertados pelo processo para melhor proferir sua decisão ZIMERMAN; COLTRO, 2002b, p. 585-586). Daí resulta a importância, segundo o autor, de o juiz fazer uma dissociação útil do ego, isto é, mesmo que esteja passando por alguma crise emocional, o juiz deve intimamente reconhecer e assumir o que se passa consigo e "manter bem separados o homem que tem plenos direitos a toda ordem de sentimentos e o profissional que deve manter a sua neutralidade, disponibilidade e um verdadeiro interesse na sua função" (ZIMERMAN; COLTRO, 2002b, p. 590).

No mesmo sentido, José Osmir Fiorelli e Rosana Cathya Ragazzoni Mangini (2009, p. 174) advertem que quando o juiz se deixa dominar pela emoção compromete percepção, atenção, pensamento e memória, abrindo-se espaço para enganos de raciocínio, falhas de percepção, lapsos e outros fenômenos psíquicos que sujeitam o julgador a crenças inadequadas, esquemas rígidos de pensamento, pensamentos automáticos, preconceitos e mecanismos de defesa que comprometem o desempenho do seu papel profissional.

\section{Os valores sociais e a decisão}

Outro desafio daquele que julga é desvencilhar-se dos efeitos do social sobre si. Falar de subjetividade humana é falar da objetividade em que vivem os homens. A compreensão do mundo interno exige a compreensão do mundo externo, pois são dois aspectos de um mesmo processo no qual o homem atua e constrói/modifica o mundo, e este, por sua vez, propicia os elementos para a constituição psicológica do homem. Assim, o mundo psicológico do juiz está em relação dialética com o mundo social. 
A percepção desse fenômeno social é de fundamental importância para a identificação de preconceitos e estigmas arraigados no senso comum.

Os valores sociais exercem indiscutível influência sobre as pessoas, no entanto, o juiz deve estar atento para não assumir postura inadequada ou indesejada para a própria sociedade. $\mathrm{O}$ julgador não pode se furtar ao processo de autoconhecimento para reconhecer como reage aos estímulos tanto internos quanto àqueles advindos do meio externo. A eficácia de seu desempenho prático depende não apenas de uma sólida formação teórica como do bom conhecimento e controle dos aspectos emocionais que permeiam todos os relacionamentos profissionais ou não. Assim, o psiquismo do juiz é um aspecto fundamental na sentença e essa indevida influência pode ser controlada se os julgadores estiverem dispostos a se analisarem.

David Zimerman afirma que o juiz sofre três tipos de pressão: a) pressões exteriores de origem extraprofissional (familiares, socioeconômicas, financeiras); b) pressões exteriores de ordem profissional (demanda excessiva de trabalho, comarcas que não são as de sua livre preferência ou de sua livre escolha, salários inadequados, relações conflituosas com colegas de trabalho); e c) pressões interiores, conscientes ou não (desejos, ansiedade, amor, ódio, vingança, ciúmes, desconfiança, culpa, desatualização diante das mudanças legislativas e tecnológicas, frustração por não ter atingido as metas com que sempre sonhou, etc.). Essas pressões tendem a levar a crises emocionais que podem ser de resolução sadia e de crescimento positivo, mas, também, podem ser patológicas e mutilantes. Para amenizar o sofrimento e o desgaste resultante do estresse emocional, esse autor indica medicação da psicofarmacologia moderna, alguma modalidade de psicoterapia e a prática de grupos de reflexão (FIORELLI; MANGINI, 2009, p. 115).

\section{Os interesses que motivam uma ação judicial}

O controle das emoções pelo juiz também é importante para desvendar os verdadeiros interesses que se escondem atrás de uma ação 
judicial. Muitos são os sentimentos que motivam um processo judicial: ódio, vingança, necessidades financeiras, sentimento de justiça, desejo de desculpas, dentre outros. Além disso, as características das partes (valores, motivações, aspirações, objetivos, recursos físicos, intelectuais e sociais, crenças, expectativas), o relacionamento anterior havido entre os litigantes e o próprio ambiente social interferem diretamente no conflito.

A apuração da verdade fica muito mais fácil quando o juiz descobre a causa psicológica da pretensão. Por isso, afirma-se que deve existir sintonia emocional (ZIMERMAN, 2002a, p. 112) entre o juiz e o entrevistado, a fim de que o julgador possa: perceber e interpretar as emoções que dominam os indivíduos e os efeitos que elas possam ocasionar em seu comportamento; identificar informações relevantes para a busca da verdade; formular questões adequadas à elaboração mental dos indivíduos; e utilizar uma linguagem compreensível pelo entrevistado.

Da mesma forma, a análise prévia do tipo de personalidade e das relações afetivas da testemunha permite verificar se o testemunho é ou não imparcial. Entender a extensão com que ocorrem as interferências emocionais sobre o testemunho aumenta as chances de melhor lidar com a testemunha e obter dela um relato fático que seja mais próximo possível da realidade. Esse conhecimento ainda auxilia o julgador no papel de conciliador, permitindo o oferecimento de propostas com ganhos mútuos e com maiores chances de aceitação pelas partes.

Além disso, o juiz decide com base na realidade produzida pelas partes no processo, interpretada por seus fenômenos mentais e pelos modelos culturais existentes no ambiente social. É importante que o magistrado tenha conhecimento de que a realidade exposta pela parte é fruto de seu subjetivismo, na medida em que os indivíduos interpretam os fatos de acordo com suas tendências afetivas (MIRA Y LOPEZ, 2009, p. 144). Nem sempre a realidade efetiva dos acontecimentos guarda relação direta com a realidade psíquica das partes. Um mesmo fato pode gerar diferentes interpretações, pois cada indivíduo possui uma visão particular de mundo influenciada por fatores que vão desde o aparelho sensório de cada pessoa até o contexto social e cultural em que ela está inserida.

Rev. Direito Econ. Socioambiental, Curitiba, v. 3, n. 2, p. 491-503, jul./dez. 2012 
A realidade efetiva sofre tanto a deformação voluntária e consciente do indivíduo como a distorção involuntária decorrente da afetividade própria da cada pessoa. Os estímulos ambientais são interpretados pelas pessoas, de modo que um mesmo conjunto de estímulos pode gerar diferentes percepções em diferentes pessoas. As experiências passadas, os valores, as crenças, os conhecimentos, as características dos estímulos, os processos inconsciente, as expectativas, a violência e o estado emocional, dentre outros, são fatores que afetam profundamente a interpretação das informações pelo cérebro. Assim, em verdade, é a realidade psíquica, elaborada pelos conteúdos mentais dos indivíduos, que é trazida ao processo para julgamento pelo juiz.

Esse fenômeno de distorção subjetiva da realidade também afeta testemunhas, principalmente porque o processo de armazenamento das informações continua a sofrer atuação de outros fatores, como crenças, padrões, experiências vividas, novas informações, dentre outros. Quanto mais emotiva e intensa for a situação, menos a testemunha se recordará dos detalhes do fato, pois o que se observa é a atuação de mecanismos psíquicos inconscientes do indivíduo que impõem o esquecimento de fatos traumáticos e dolorosos. Além disso, verifica-se uma diminuição no grau de retenção das informações à medida que o tempo passa.

Assim, a construção da realidade efetiva depende do trabalho do juiz de confrontação dos depoimentos das partes, das testemunhas e de todos os elementos de prova trazidos aos autos. Trata-se de uma espécie de trabalho seletivo em que as semelhanças e coincidências são agrupadas para a apreensão dos eventos fáticos, afastando-se as predisposições perceptivas e emocionais das partes e testemunhas. No entanto, é importante ressaltar que esse trabalho de seleção do material sobre o qual será proferido o julgamento depende da percepção do magistrado, pois somente será analisado aquilo que conseguiu adentrar a consciência do julgador. Em outras palavras, elementos importantes para o processo podem ser ignorados, pois não foram considerados relevantes para o juiz, conforme seu processo subjetivo de focalização da percepção. Esse fenômeno pode se dar fora da consciência do magistrado, que deve ficar atento para 
considerar todos os elementos presentes no processo, ao mesmo tempo que deve cuidar para não se perder com detalhes desnecessários que acabem por desviá-lo da compreensão das provas mais importantes.

Além disso, o juiz representa o poder do Estado em determinar os destinos das pessoas, despertando no imaginário popular sentimentos de respeito, receio e admiração. Nos tempos atuais, o Poder Judiciário se transformou em uma espécie de tábua de salvação para os mais diversificados males que atormentam a alma humana. Conquanto todas as esperanças sejam depositadas na decisão judicial, prolatar sentenças nem sempre significa pacificar conflitos. Por isso, David Zimerman adverte que o juiz deve reconhecer que tem limites, limitações e tem direito de cometer erros, o que não se confunde com uma postura de negligência (ZIMERMAN, $2002 b$, p. 584). Essa representação social da figura do juiz deve ser percebida pelo julgador para não fomentar o desequilíbrio emocional próprio, das partes e das testemunhas.

A compreensão desse aspecto também é importante para o juiz perceber que muitas pessoas necessitam se sentir protegidas no ambiente da sala de audiências, não sendo raras as situações em que testemunhas relatam ter se esquecido dos fatos perante o magistrado. Ao dirigir-se ao Poder Judiciário, o litigante transfere a culpa pelo sucesso ou não de sua demanda a outra pessoa a quem compete decidir a causa, pois o juiz representa para a parte a pessoa preparada para solucionar o conflito, existindo grande expectativa nas decisões. Assim, a postura do magistrado deve ser de liderança no comando do processo, mas apropriada aos litigantes, gerando no espírito destes o sentimento de verdadeiro interesse do juiz na solução justa do conflito.

\section{Considerações finais}

Em conclusão, pode-se afirmar que a realidade tem sempre um valor subjetivo e, portanto, relativo, pois é deformada pelos processos psíquicos das pessoas envolvidas. Essa realidade, sobre a qual deve se pronunciar o julgamento, ainda é apreciada pela personalidade do julgador, pois

Rev. Direito Econ. Socioambiental, Curitiba, v. 3, n. 2, p. 491-503, jul./dez. 2012 
este decide com base naquilo que adentrou, pela percepção, o mundo da sua consciência. O processo perceptivo, por sua vez, se dá sob a influência de diversos fatores, alguns inconscientes e provenientes do ambiente social em que os homens estão inseridos. Assim, cabe ao juiz selecionar com atenção o material sobre o qual pronunciará o seu juízo e, conquanto não possa afastar totalmente suas emoções do produto do julgamento, deve estar atento a esse processo de interferência emocional, evitando atitudes precipitadas, rejeição de elementos importantes para o processo e juízos de valores que não refletem os verdadeiros interesses da sociedade.

\section{Referências}

FIORELLI, J. O. Psicologia aplicada ao Direito. Revista do Tribunal Regional do Trabalho da 24ª Região, n. 15, p. 55-73, 2010.

FIORELLI, J. O.; MANGINI, R. C. R. Psicologia jurídica. São Paulo: Atlas, 2009. MIRA Y LÓPEZ, E. Manual de psicologia jurídica. São Paulo: Vida Livros, 2009.

ZIMERMAN, D. A influência dos fatores psicológicos inconscientes na decisão jurisdicional: a crise do magistrado. In: ZIMERMAN, D.; COLTRO, A. C. M. Aspectos psicológicos da atividade jurídica. Campinas: Millennium, 2002a. p. 11-143.

ZIMERMAN, D. Uma aproximação entre o perfil da figura do juiz de direito e a do psicanalista. In: ZIMERMAN, D.; COLTRO, A. C. M. Aspectos psicológicos da atividade jurídica. Campinas: Millennium, 2002b. p. 583-625.

Recebido: 30/11/2009

Received: 11/30/2009

Aprovado: $12 / 07 / 2012$

Approved: 07/12/2012 